\title{
A Review of the ACHS Clinical Indicator Program after 20 years
}

\author{
B Collopy, C Dennis, L O'Connor and M Nathan
}

\begin{abstract}
The Clinical Indicator Program, which was introduced into the Australian Council on Healthcare Standards' accreditation program two decades ago, has grown from one set addressed by 115 healthcare organisations to 22 sets with data received from over $\mathbf{8 0 0}$ healthcare organisations, resulting in a national database which is unique in its clinical diversity, reflecting every major medical discipline involved in hospital practice. The process for Clinical Indicator selection and review remains with the providers of the care, but the selection criteria are better defined and the evidence base strengthened. Early responses to their introduction were encouraging as improvements in patient management and outcomes were sought and achieved following review of comparative data, and some examples of these are provided. Clinical Indicator revision remains an important and major task and the original HospitalWide set of Clinical Indicators is now in its 12 th version. The development and use of Clinical Indicators is increasing world-wide, and in Australia there are other organisations, including the Australian Commission on
\end{abstract}

Safety and Quality in Healthcare, looking at Clinical Indicators to further understand the performance of healthcare organisations.

As clinical care changes, the challenges for the Australian Council on Healthcare Standards are to ensure the Clinical Indicators continue to reflect current practice, to retain clinician support, and also to ensure that the existence of its extensive and long-standing national clinical database is more widely known and utilised.

Abbreviations: ACHS: Australian Council of Healthcare Standards; ACIR - Australasian Clinical Indicator Report; ANZICS - Australian and New Zealand Intensive Care Society; APD - Adult Patient Database; Cl - Clinical Indicators; HCO - HealthCare Organisation; PIRT Performance Indicator Reporting Tool; RACMA - Royal Australian College of Medical Administrators.

Key words: clinical indicators; accreditation; clinical databases.

\section{Brian Collopy FRACS FRACMA}

Clinical Advisor - Performance and Outcomes Service, Australian Council on Healthcare Standards

\section{Christine Dennis MHSM DBA}

Chief Executive Officer

Australian Council on Healthcare Standards Adjunct Associate Professor Faculty of Sciences Flinders University

\section{Linda O'Connor BAppSc MA}

Executive Director - Customer Services and Development Australian Council on Healthcare Standards

\section{Myu Nathan BSc MPH}

Manager- Performance and Outcomes Service Australian Council on Healthcare Standards

Correspondence:

bcollopy@achs.org.au 


\section{Introduction}

Twenty-two years ago the first set of Clinical Indicators (Cls) was introduced into the Australian Council on Healthcare Standards (ACHS) accreditation program. Initial support came from the Commonwealth Department of Health, which provided a total of approximately $\$ 2.2$ million (in three yearly development grants) over a decade, and from Baxter Healthcare P/L. The co-operation of the Medical Colleges enabled relevant clinician input into the $\mathrm{Cl}$ development.

This paper is written for the benefit of both healthcare administrators and clinicians, particularly for those involved in quality review and what is currently termed 'clinical governance', to inform of the changes which have occurred since the introduction of the program with regard to its growth, the $\mathrm{Cl}$ development and revision process, the supporting information provided for contributors, the data collection process, the database itself and the changes in clinical practice, which are reflected in the data and which, to some extent, may have resulted from a process which allows for self (over time) and peer comparison.

Twenty-one years ago data from 115 healthcare organisations (HCOs) on one set containing 15 Hospital-Wide $\mathrm{Cls}$ were released. The $\mathrm{Cls}$ had been developed with the co-operation of the Royal Australian (now Australasian) College of Medical Administrators (RACMA). It was a world first for accreditation programs. Currently data are received from over $800 \mathrm{HCO}$ on 22 indicator sets containing over 300 individual Cls. All major disciplines are represented and the national clinical database, in its diversity, is the most comprehensive of its type in the world. The last printed report of the aggregate results was in 2003. If produced in hardcopy now it would amount to well over 600 pages. However the report is available annually via the internet or on $C D$ and a hard copy summary of results remains available as the Australasian Clinical Indicator Report (ACIR) [1] (Australasian as a number of New Zealand HCOs now participate in the Clinical Indicator Program). Considering that the provision of $\mathrm{Cl}$ data by $\mathrm{HCO}$ is voluntary that is a significant achievement.

The ACHS now assists HCOs in data reporting through the provision of the Performance Indicator Reporting Tool (PIRT) and analysis of the data is performed externally each year for the ACHS by the Health Services Research Group at the University of Newcastle. Trending of data is only performed when there are four or more years of data available.
The program was introduced to measure and improve the quality of care, to increase clinician interest and involvement in quality activities and to lessen the possibility of an $\mathrm{HCO}$ receiving full accreditation and yet having poor patient management and outcomes.

\section{Clinical Indicator selection}

Content validity of the indicators is assured by their being provider developed. Three criteria were required in the development of a $\mathrm{Cl}$, namely that the subject chosen was of clinical importance, that data were available for its assessment and that as a $\mathrm{Cl}$ it was responsive, i.e. that it could induce a change in clinical practice. These criteria remain appropriate to use today. In more detail they are:

1. Clinical significance

1.1 Disease burden (volume, cost, concern)

1.2 Content validity (measure of quality)

1.3 Evidence base (level of evidence)

2. Data value

2.1 Data elements (definable, accessible)

2.2 Reliability (accurate, reproducible)

3. Responsiveness (potential to improve care).

The $\mathrm{Cls}$ in this program address either the process of care such as a medication requirement, or the outcome of care such as a wound infection. The advantage of an outcome $\mathrm{Cl}$ is that it is important in its own right, but disadvantages are that sufficient numbers are required to reduce chance variation, and that case-mix and illness severity may require determination. [2] An advantage of process measures is that the facility can act upon findings more quickly, however the value of the process selected as a $\mathrm{Cl}$ should be evidencebased, as all of the current Cls are. In addition to addressing issues considered of importance by the providers of care and being supported by a comprehensive literature review, each set is endorsed by the relevant Medical College/Society prior to its release in a User Manual. The basic structure of a $\mathrm{Cl}$ is shown in Box 1, together with the type of supporting information contained in the User Manual for each area of clinical activity being addressed.

\section{HCO responses}

Although provision of $\mathrm{Cl}$ data is voluntary, $\mathrm{HCO}$ are expected to provide data concerning their main service areas. Contributing $\mathrm{HCO}$ s receive six-monthly reports containing their results for the period, together with aggregate and peer comparative data. In 2014 the average number of individual $\mathrm{Cls}$ reported by HCOs was 22 . 
Box 1: An indicator in the area of cardiovascular disease and the type of information provided in the User Manual for Internal Medicine Clinical Indicators Version 6

\section{Congestive Heart Failure (CHF) - prescribed beta blocker}

\begin{tabular}{|l|l|}
\hline \multicolumn{1}{|c|}{ CLINICAL INDICATOR } & \multicolumn{1}{c|}{ USER MANUAL SUPPORT } \\
\hline $\begin{array}{l}\text { Numerator - Number of patients discharged with a } \\
\text { diagnosis of CHF who have no contraindications to use } \\
\text { of beta blockers and who are prescribed beta blocker } \\
\text { therapy, during the } 6 \text { month time period }\end{array}$ & $\begin{array}{l}\text { - Rationale } \\
\text { - Reporting period }\end{array}$ \\
$\begin{array}{l}\text { Denominator - Number of patients discharged with } \\
\text { a diagnosis of CHF and who have no contraindications } \\
\text { to use of beta blockers, during the } 6 \text { month time period }\end{array}$ & \begin{tabular}{l} 
• Data cleaning rules \\
\hline
\end{tabular} \\
\hline
\end{tabular}

In the early years of the program the ACHS received quantitative and qualitative data, the latter allowing it to determine the $\mathrm{HCOs}^{\prime}$ responses to receiving aggregate and, in particular, peer comparative data. Responses could be classified into five groups:

- review of data accuracy e.g. a further internal audit

- policy and procedure changes e.g. a change in antibiotic prophylaxis

- education programs e.g. on thromboembolism prophylaxis

- new appointments e.g. a discharge planning officer

- equipment changes e.g. new type of catheter etc. [3]

Surveys of HCOs in 2014 and 2015 revealed that the above five types of response are still occurring.

\section{Changes in clinical practice}

Trends can be demonstrated in the ACHS national clinical database showing that HCOs appear to be responding to a review of their results and are improving the care provided. Of 197 Cls available for trending in the 2014 data, over 50\% showed a trend in a desirable direction and in five of the indicator sets more than two-thirds of all their trended $\mathrm{Cls}$ showed improvement. [1] Analysis of 2015 data had not been completed at the time of submission of this paper.

Cls certainly reflect changes in patient management, for example with a $\mathrm{Cl}$ requiring patients admitted with an acute myocardial infarct (now termed acute coronary syndrome), to receive thrombolysis within one hour, the compliance rate rose from $70 \%$ on its introduction to a maximum of approximately $80 \%$ in 2008 , but steadily fell from that year to approximately $60 \%$ in 2014 , due to the development of early percutaneous coronary intervention $(\mathrm{PCl})$. This $\mathrm{Cl}$ will remain for $\mathrm{HCO}$ s without $\mathrm{PCI}$ facilities and those with them will address the 'door to balloon time'.
However, that the introduction of a $\mathrm{Cl}$ has affected change and not simply reflected it, is suggested with the $\mathrm{Cl}$ addressing the compliance rate in the provision of antibiotic prophylaxis for caesarean section. This was below $60 \%$ in 2008 , when the $\mathrm{Cl}$ was introduced, and rose to over $90 \%$ by 2012, a level that has been maintained since. This early'slope of improvement' can be demonstrated with many of the Cls. Some other examples of statistically significant improvement over time in patient care are shown in Table 1, which lists the aggregate rates reported in 2007 and 2014 for seven Cls, which, having not been revised over that period, can be compared. The 2014 denominators for these seven Cls varied from approximately 11,000 patients (from $20 \mathrm{HCOs)}$ for the Hospital in the Home $\mathrm{Cl}$ to over 445,000 patients (from $144 \mathrm{HCOs}$ ) for the Emergency Medicine $\mathrm{Cl}$.

Cost-avoidance can also be shown, for example with the generic Cl 'Unplanned Readmission'. The rate in 1998 was approximately $2.2 \%$ and in 2014 it was $1.17 \%$. The cost avoidance (through the decreased rate) for the year 2014 would amount to over $\$ 200$ million. Whilst fewer HCOs reported data in 2014 than in 1998, there was a 40\% increase in the number of patients in the denominator (over 3.25 million) for 2014. In addition to improvements in medical and nursing practice, which would have occurred over that time, it is also likely that the introduction of the unplanned re-admissions $\mathrm{Cl}$ had some influence through the action taken by HCOs of employing nurse discharge planners.

\section{Clinical Indicator revision}

As medical care evolves and improves one constant challenge, from the program's inception, was ensuring that the Cls remained current and that the support and participation of clinicians were maintained. An example of the need for currency is the thrombolysis vs $\mathrm{PCl}$ issue mentioned above. Much time, effort and funding have been 
Table 1. Comparison of Selected Cl data from 2007 and 2014

\begin{tabular}{|c|c|c|c|}
\hline INDICATOR SET & CLINICAL INDICATOR & 2007 RATE & 2014 RATE* \\
\hline Emergency Medicine & $\begin{array}{l}\text { ATS Category } 2 \text { patients attended } \\
\text { within } 10 \text { minutes }\end{array}$ & 74.7 & 80.5 \\
\hline Gynaecology & $\begin{array}{l}\text { Unplanned blood tranfuion with gynaecological } \\
\text { surgery for benign disease }\end{array}$ & $1.3 \%$ & $80.5 \%$ \\
\hline Hospital-Wide & Significant adverse blood transfusion events & $0.27 \%$ & $0.18 \%$ \\
\hline $\begin{array}{l}\text { Hospital in the Home } \\
\qquad(\mathrm{HITH})\end{array}$ & Patients having 1 unscheduled staff callout & $1.38 \%$ & $0.54 \%$ \\
\hline ICU & $\begin{array}{l}\text { Adult patients transferred to another facility } \\
\text { due to bed unavailability }\end{array}$ & $1.28 \%$ & $0.77 \%$ \\
\hline Infection Control & $\begin{array}{l}\text { Combined superficial and deep infection following } \\
\text { hip prosthesis procedures }\end{array}$ & $0.89 \%$ & $0.47 \%$ \\
\hline Mental Health Inpatient & $\begin{array}{c}\text { Inpatient discharged on }>3 \text { pychotropic } \\
\text { medications }\end{array}$ & $9.79 \%$ & $4.1 \%$ \\
\hline
\end{tabular}

*All 2014 rates shown differ significantly from those for 2007

directed at periodic revision of the $\mathrm{Cl}$ sets, such that nine sets are in their fifth or more version and the first set introduced, the Hospital-Wide Cls, is in its twelfth year. The revisions are now performed by relevant multidisciplinary working parties plus a consumer, and still require approval by the relevant Medical (and Nursing) College or Society before their adoption. Unfortunately, despite ACHS efforts, the Surgical set of Cls was not revised for over a decade [4] and the Royal Australasian College of Surgeons is now more supportive of national audits conducted in specific disciplines, such as vascular surgery. Some of the Surgical Cls are able to be addressed in the Hospital-Wide set, for management of patients undergoing complex procedures, such as coronary artery grafts, is essentially multidisciplinary. Data on $21 \mathrm{Cls}$ (across three $\mathrm{Cl}$ sets) reflecting surgical practice will continue to be collected.

If an external audit replaces a $\mathrm{Cl}$ process, an accrediting body should be reassured when surveying an HCO that audit information would be:

- current and available at the time of survey

- inclusive of relevant providers in the HCO being surveyed

- cover the majority of procedures performed in a particular time frame

- contain morbidity and mortality data relevant to the HCO

- enable comparative data review with peer HCOs.

In its inaugural year of 2010 the Australasian Vascular Surgical Audit captured 65\% of procedures performed. [5] For elective open repair of an abdominal aortic aneurysm there were 573 procedures reported with an in-hospital mortality of $2.4 \%$. The ACHS data reported 696 procedures in the same year with a mortality rate below $2 \%$. [4] It had been just over $3 \%$ for the previous decade and it is likely that the fall was due to the inclusion in the ACHS data of some percutaneous repairs, as the requirement that only 'open' repairs are reported has just recently been included in the ACHS Cl. This is another example of the constant need for $\mathrm{Cl}$ revision.

\section{Data accuracy}

Accuracy of the ACHS Cl data has been addressed previously. [6] Occasionally a published study provides an opportunity for comparison of results, as with a recent report on mortality related to after-hours discharge from an intensive care unit, which is also an $\mathrm{ACHS} \mathrm{Cl}$, using the Australian and New Zealand Intensive Care Society (ANZICS) Adult Patient Database (APD). [7] The mortality rates obtained in each database differed only slightly, being $15.4 \%$ for the years 2005-2012 in the ANZICS APD and 15.9\% for the years 20072013 in the ACHS database. The ACHS had no comparative data for the period 2005-2006 as the Cl was only introduced in 2007 , so the time periods could not be exactly matched. It is important to recognise that the ACHS Cl program is one of review and not research.

When a review program flags a problem and the cause is evident a recommendation can be made and a further review subsequently conducted. If the cause is not evident then a research project can be mounted, with the extra 
resources required in terms of personnel, time and funds to obtain data on every possible event, with the expectation of then determining a cause.

\section{Outliers}

Participating HCOs receive reports identifying areas where their rates differ significantly from the overall rate, i.e. where they are outliers. In 2014, as in previous years, such outliers occurred in all sets, with only around $25 \%$ of HCOs having none and 50\% having both desirable and undesirable outliers. Those HCOs that report on fewer Cls have fewer outliers.

Thus the $\mathrm{Cl}$ data aught not be used for 'League Tables', but are best used for internal reviews, which HCOs are expected to undertake.

\section{Programs in other countries}

Clinical Indicator programs have been established in North America, the United Kingdom, Europe and Asia. The list of individual countries with such programs continues to grow, confirming the value placed on $\mathrm{Cls}$ by healthcare bureaucracies world-wide. In the United States the Joint Commission introduced $\mathrm{Cls}$ into its accreditation program in 1999, having first outlined the concept in its 1987 policy 'Agenda for Change'. As with the ACHS there has been constant revision of its $\mathrm{Cls}$. Currently there are 14 sets of core measures from which North American HCOs are expected to choose the measures they will address, and their reported data may be made public. [8] Other early and quite comprehensive programs were developed in Scotland, in 1993 [9] and Denmark in 2000. [10]

\section{Other Australian programs}

A further challenge for the ACHS is that its $\mathrm{Cl}$ program remains a requisite for ensuring a high quality of patient care, as clinical performance measures are developed by various other Australian healthcare authorities. The Australian Commission on Safety and Quality in Healthcare has recently produced a set of hospital-based outcome indicators addressing inhospital mortality, re-admissions and hospital acquired infection. [11]

Whilst much information for these indicators can be obtained from administrative databases, they are limited in relation to knowledge of illness severity and preventability. For example a re-admission to hospital might be recognised as unplanned, but not that it was unexpected. This is an important advantage of the ACHS national clinical database, for not all of the apparently failed processes of care or untoward outcomes will be avoidable.

\section{Have the ACHS Cl program's aims been met?}

As stated above, improvement in the quality of care can be demonstrated in the high number of desirable trends evident in the ACHS Cl database. Indicators, such as the requirement to conduct a clinical review of obstetric adverse events, which has risen from approximately $50 \%$ of cases in 2009 having a review to $100 \%$ in 2014 , along with the limited amount of qualitative data the ACHS receives, suggest that there is strong clinician interest in quality activities. A recent online questionnaire and phone interviews concerning the use of Day Patient Cls also confirmed that $\mathrm{Cl}$ data are presented regularly to senior clinical and administrative staff and acted upon to improve patient management. [12]

Although there is no incontrovertible evidence to indicate that the likelihood of an $\mathrm{HCO}$ with inadequate patient management processes and outcomes being accredited has been lessened, significant advances in accreditation survey processes, including the requirement for HCOs to demonstrate evidence of improvement in patient management and outcomes, has significantly reduced such a likelihood.

The extensive coverage of clinical activities reflected in the ACHS Cl sets, and the important provider input in their development and revision, should ensure their continued use and influence in assessing standards of care in Australian HCOs and, most importantly, in providing a stimulus to improvement in that care. Brand et al reporting on a survey of Australian public hospitals conducted in 2005, found that $99 \%$ of the hospitals surveyed measured clinical performance, with $72 \%$ using Cls to do so. [13] Presumably the majority of the Cls used at that time were from the ACHS program. However, only a brief reference to one $\mathrm{ACHS} \mathrm{Cl}$ was made in a Medical Journal of Australia supplement in 2010 devoted to the gathering of clinical information to improve care. [14] There is clearly a challenge for the ACHS in the promotion of its unique national clinical database. It is now developing as an international database, with the recent participation of Hong Kong, Indonesia and Saudi Arabia in addition to New Zealand, although the number of HCOs participating from those countries remains small at this stage.

Given the amount of data and information available to HCOs today, the ACHS aims to ensure its data are easily interpreted, supported by healthcare personnel experienced in quality assessment and most importantly, are used by HCOs as a critical element to improve patient outcomes. As the great Dr W Edwards Deming wrote 'There is no substitute for knowledge'. [15] 


\section{Acknowledgement}

The ACHS gratefully acknowledges the input of the past and present 'chairs' and members of the many $\mathrm{Cl}$ Working Parties in the initial development of each $\mathrm{Cl}$ set and each subsequent revision.

\section{Competing interests}

The authors declare that they have no competing interests.

\section{References}

1. Australian Council on Healthcare Standards. Australasian Clinical Indicator Report. 2007-2014. 16th Edition. Sydney, Australia: ACHS; 2015.

2. Mant J. Process versus outcome indicators in the assessment of quality in healthcare. Int J Qual Healthcare. 2001;13:475-480.

3. Collopy BT. Clinical indicators in accreditation: an effective stimulus to improve patient care. Int J Qual Healthcare. 2000;12:211-216.

4. Collopy BT, Bichel-Findlay JM, Woodruff PWH, Gibberd RW. Clinical Indicators in surgery: a critical review of the Australian experience. ANZ J Surg. 2014;84:42-46.

5. Beiles CB, Bourke B, Thomson I. Results from the Australasian Vascular Surgical Audit. ANZ J Surg. 2012;82:105-111.

6. Booth JL, Collopy BT. A national clinical database: issues of reliability and validity. Aust Health Rev. 1997;20:84-95.

7. Gantner D, Farley KJ, Bailey M, et al. Mortality related to after-hours discharge from intensive care in Australia and New Zealand, 20052012. Intensive Care Med. (published online 15 August 2014).

8. Core Measure Sets (accessed April 2015) Available from: www.joint commission.org/core_measure_sets.aspx

9. A Draft National Strategy for Clinical Indicators in Scotland (accessed April 2015).

10. Mainz J, Bartels PD. National quality measurement using clinica indicators: the Danish national Indicator Project. J Surg Oncol. 2009;99:500-504.

11. Australian Commission on Safety and Quality in Healthcare. Windows into safety and quality in healthcare. 2009. Sydney, NSW: ACSQHC; 2009.

12. Collopy BT, Day Patient Clinical Indicators. A good news story with a cautionary tale. ACIR 16th Edition 2007-14. Australian Council on Healthcare Standards.(in press)

13. Brand CA, Tropea J, Ibrahim JE, et al. Measurement for improvement: a survey of current practice in Australian public hospitals. Med J Aust. 2008; 189:35-40.

14. Johnson NP, Board N (co-ordinating editors). Using what we gather-information for improved care. Med J Aust. 2010;193: S89-S120.

15. Deming WE. The New Economics: for Industry Government Education. 2nd Edition. MIT Press: 2000. 